\title{
Morphological and topographical anatomy of nutrient foramina in human clavicles and their clinical importance
}

\author{
Rahul Rai ${ }^{1}$, Shailaza Shrestha ${ }^{2}$, B Kavitha ${ }^{3}$ \\ 1(Department of Anatomy, Career Institute of Medical Sciences and Hospital, INDIA) \\ 2(Department of Biochemistry, Goldfield Institute of Medical Sciences and Research, INDIA) \\ 3(Department of Pharmacology, Goldfield Institute of Medical Sciences and Research, INDIA)
}

\begin{abstract}
The aim of our study was to determine the number, direction, position of nutrient foramen and whether the nutrient foramina obey the general rule that is, directed away from the growing end of the bone. The study comprised 40 clavicles, which were obtained from the anatomy department of Career Institute of Medical Sciences and Hospital. The clavicles were macroscopically observed for the number, location and direction of the nutrient foramina. The foramen index was calculated for each clavicle by applying the Hughes formula. The neurovascular foramen was observed in all 40 (100\%) clavicles. Total 65 foramina were observed. $15.4 \%$ foramen was present at the medial $1 / 3^{\text {rd }}$ region, $73.8 \%$ at the middle $1 / 3^{\text {rd }}$ region and $10.8 \%$ at the lateral $1 / 3^{\text {rd }}$ of clavicles. $35.4 \%$ foramen were on inferior and $64.6 \%$ foramen were on posterior surface of clavicles. The foramen was single in 17 (42.5\%) clavicles, double in 21 cases (52.5\%), and there were more than 2 foramina in 2 clavicles $(5 \%)$. The foramen was present at the medial $1 / 3^{\text {rd }}$ region in $19.2 \%$ clavicles, at the middle $1 / 3^{\text {rd }}$ region in $67.3 \%$ and at the lateral $1 / 3^{\text {rd }}$ part in $13.5 \%$ clavicles. It was on the inferior surface in $42.6 \%$ clavicles and on the posterior surface in $57.4 \%$. The average distance of the foramen from the sternal end was $6.76 \mathrm{~cm}(67.6 \mathrm{~mm})$ and the mean foraminal index was 48.01. Nutrient foramina play an important role in nutrition and growth of the bones. The knowledge of nutrient foramen is important in surgical procedures like bone grafting and in microsurgical vascularised bone transplantation.
\end{abstract}

Key words: Clavicle, nutrient foramen, foramen index, sternal end, acromial end

\section{Introduction}

The clavicle is well known long, curved bone which is situated subcutaneously across the root of the neck. Usually shaft of clavicle contain only one significant canal which transmits the main nutrient artery of the bone. Sometimes as an interesting finding, well defined canals perforating the clavicle entirely may be established. These canals are the result of the variant passing of supraclavicular nerves through the clavicle [1]. The role of nutrient foramen in nutrition and growth of the bones is evident from term "Nutrient" itself [2]. Nutrient foramen is the largest foramen on the shaft of long bones through which nutrient artery for that bone passes [3]. The nutrient artery is the principal source of blood to a long bone particularly during its active growth period [4,5]. Most of the nutrient arteries follow the rule, 'to the elbow I go, from the knee I flee' but they are very variable in position. This is because one end of limb bone grows faster than the other do [6]. Nutrient canal (through which nutrient artery enters the shaft) typically become slanted during growth, the direction of slant from surface to marrow cavity points towards the end that has grown least rapidly. This is due to greater longitudinal growth at the faster growing end. All long bones including clavicle have two epiphysial ends while miniature long bones have only one growing end. The direction of nutrient foramen of all bones is away from growing end [7]. Berard was the first to correlate the direction of the canal with the ossification and growth of the bone [8]. Humphrey who worked on the direction and obliquity of nutrient canals postulated periosteal slipping theory, the canal finally directed away from the growing end [9]. Harris has stated that the position of nutrient foramina is constant during the growth of long bone [10]. Lutken has stated that position of nutrient foramina is variable \& typical position of nutrient foramina can be determined after a study on human bones [11].

The topographical knowledge of these foramina is useful in certain operative procedures to preserve the circulation [12]. It is important that the arterial supply be preserved in free vascularized bone grafts, so that the osteocytes and osteoblasts survive [13]. With the knowledge of variations in the nutrient foramen, placement of internal fixation devices can be appropriately done [14].

\section{Materials and Methods}

The study comprised 40 clavicles, which were obtained from the department of anatomy, Career Institute of Medical Sciences and Hospital, Lucknow. The clavicles were macroscopically observed for the number, location and direction of the nutrient foramina. The distance of foramina from sternal end was also determined. The foramen index was calculated for each clavicle by applying the Hughes formula, dividing the 
distance of the foramen from the proximal end (D) by the total length of the bone (L) which was then multiplied by hundred:

$\mathrm{FI}=\mathrm{D} / \mathrm{L} \quad \times 100 \ldots \ldots \ldots \ldots . .(1)[15]$.

\section{Results}

The nutrient foramen was observed in $40(100 \%)$ clavicles. The foramen was single in $17(42.5 \%)$ clavicles, double in 13 cases (52.5\%), and there were more than 2 foramina in 2 clavicles (5\%). Most of the right clavicles contained single foramina (50\%) whereas left clavicles contained double foramina $(62.5 \%)$. Three foramen could be obtained in only two clavicles and that was in the right sided clavicle (Table 1).

Table 1. Number of nutrient foramina in clavicle

\begin{tabular}{|c|c|c|c|}
\hline \multirow{2}{*}{$\begin{array}{c}\text { NUMBER OF NUTRIENT } \\
\text { FORAMEN }\end{array}$} & \multicolumn{3}{|c|}{ CLAVICLE } \\
\cline { 2 - 4 } & RIGHT $(\mathrm{n}=16)$ & LEFT $(\mathrm{n}=24)$ & TOTAL $(\mathrm{n}=40)$ \\
\hline 1 & $8(50 \%)$ & $9(37.5 \%)$ & $17(42.5 \%)$ \\
\hline 2 & $6(37.5 \%)$ & $15(62.5 \%)$ & $21(52.5 \%)$ \\
\hline 3 & $2(12.5 \%)$ & - & $2(5 \%)$ \\
\hline
\end{tabular}

Total number of nutrient foramen observed was 65 . Out of which, $35.4 \%$ foramen were on inferior surface and $64.6 \%$ foramen were on posterior surface of the clavicles. Similarly when percentage of clavicle was determined we found $57.4 \%$ of clavicles contained nutrient foramen on posterior surface and $42.6 \%$ clavicles on inferior surface. Total number of clavicle considered was 54 as some clavicles contained nutrient foramen on both posterior and inferior surface (Table 2).

Table 2. Location of foramen

\begin{tabular}{|c|c|c|}
\hline SURFACE & NUMBER OF NUTRIENT FORAMEN & NUMBER OF CLAVICLE \\
\hline INFERIOR & $23(35.4 \%)$ & $23(42.6 \%)$ \\
\hline POSTERIOR & $42(64.6 \%)$ & $31(57.4 \%)$ \\
\hline TOTAL & 65 & 54 \\
\hline
\end{tabular}

$15.4 \%$ foramens were present at the medial $1 / 3$ region, $73.8 \%$ at the middle $1 / 3$ region and $10.8 \%$ at the lateral $1 / 3$ part. Likewise we also calculated percentage of clavicle containing these foramens at different regions of clavicle. Total number of clavicle considered was 52 as some clavicle contained more than one foramina located at different parts (medial, middle or lateral). We found that $67.3 \%$ of clavicle contained nutrient foramen in middle one third region, $19.2 \%$ contained on medial one third and $13.5 \%$ on lateral one third (Table 3).

Table 3. Length wise distribution

\begin{tabular}{|c|c|c|}
\hline PART OF CLAVICLE & NUMBER OF NUTRIENT FORAMEN & NUMBER OF CLEVICLE \\
\hline MEDIAL THIRD & $10(15.4 \%)$ & $10(19.2 \%)$ \\
\hline MIDDLE THIRD & $48(73.8 \%)$ & $35(67.3 \%)$ \\
\hline LATERAL THIRD & $7(10.8 \%)$ & $7(13.5 \%)$ \\
\hline TOTAL & 65 & 52 \\
\hline
\end{tabular}

The average distance of the foramen from the sternal end was $67.6 \mathrm{~mm}(6.76 \mathrm{~cm})$ and the mean foraminal index was 48.01. All the foramens were directed away from the growing end (Table 4 and 5). 
Table 4. Distance from sternal end and foramen index (FI)

\begin{tabular}{|c|c|c|}
\hline END & DISTANCE & FORAMEN INDEX \\
\hline STERNAL & $6.76 \mathrm{~cm}$ & 48.01 \\
\hline
\end{tabular}

Table 5. Direction of the nutrient foramen

\begin{tabular}{|c|c|c|}
\hline CLAVICLE & Towards growing end & Away from growing end \\
\hline $\mathrm{N}=40$ & - & 40 \\
\hline
\end{tabular}

\section{Discussion}

The external opening of the nutrient canal, usually referred to as the nutrient foramen, has a particular position for each bone [16]. In our study, all the clavicles collected contained atleast one nutrient foramen. Total number of foramen in clavicles was 65 and we found that most of the clavicles $(52.5 \%)$ contained double foramen. Most of the foramina were in middle third region and in posterior surface $(73.8 \%$ and $67.3 \%)$. Similarly most of clavicles were also found to contain nutrient foramen in middle third region and in posterior surface $(64.6 \%$ and $57.4 \%)$.

Longia GS etal observed that the position of nutrient foramina was on the flexor aspect in their human long bone specimens [17]. It is generally agreed that the vessels which occupy the nutrient foramen are derived from those that took part in the initial invasion of the ossifying cartilage. So that the nutrient foramen was at the site of original centre of ossification [16]. The well-known factors, which may affect nutrient foramen position, are the growth rates at the two ends of the shaft and bone remodeling [18]. Lacroix P suggested that the pull of muscle attachments on periosteum explained certain anomalous nutrient foramina directions [19]. Nutrient arteries, which are the main blood supply to long bones, are particularly vital during the active growth period and at the early phases of ossification [20]. These nutrient arteries pass through the nutrient foramina. The positions of nutrient foramina in mammalian bones are variable and may alter during the growth [18].

Variations in the direction of nutrient foramina have been observed in many tetrapods and there is some similarity in the foraminal pattern in mammals and birds [15]. Schwalbe G explained that growth at the two ends of a long bone before the appearance of the epiphyses is equal. Hence, the nutrient foramen before the birth should be directed horizontally [21]. Many theories have been put forward to account for the direction of the foramina and also the anomalously directed ones. Among them, the 'periosteal slip' theory of Schwalbe [21] and the vascular theory of Hughes [15] are widely accepted in the literature. Longia GS etal stated that the vascular theory offers the best explanation of all reported anomalies as well as the normal fashioning of nutrient canals [16]. Patake SM and Mysorekar VR opined that the number of foramina does not seem to have any significant relation to the length of the bone. They described that the number of foramina may not have relation to the number of ossification centers, because the femur, which is having one primary centre, usually has two foramina and clavicle, with two primary centers, has generally a single foramen [22]. It was suggested that the direction of nutrient foramina is determined by growing end of the bone. The growing end is supposed to grow at least twice as fast as the other end [4]. In our study the direction of nutrient foramen was away from the growing end. Malukar $\mathrm{O}$ etal in their sudy of 100 clavicles found that nutrient foramen was directed away from growing end in $99 \%$ of clavicles [7]. Similarly Murlimaju BV etal reported that nutrient foramen in clavicle was directed towards the acromial end [23].

In this present study the average distance of the foramen from sternal end was found to be $6.76 \mathrm{~cm}$ $(67.6 \mathrm{~mm})$ and the foramen index to be 48.01. Our finding was similar to that of Murlimanju BV etal who found the average distance of the nutrient foramen from the sternal end to be $64.4 \mathrm{~mm}$ and the mean foraminal index to be 44.72. The foramen gives the location of the nutrient foramen [23].

\section{Conclusion}

Most of the clavicles contained nutrient foramina at middle one third region and on posterior surface. The foramen index was 48.01. It gives the position of the nutrient foramen. It is necessary to have knowledge about these foramina as it is useful in the surgical procedures to preserve the circulation. The findings of our study may be useful for the clinicians who are involved in bone graft surgical procedures. The anatomical data of this subject is enlightening to the clinicians as the microvascular bone transfer is becoming more popular. 


\section{References}

[1]. Jelev L, Surchev L. Canal through the clavicle-result of the variant passing of the supraclavicular nerves, First study in Bulgaria. Medicine morphologie. 2004; 57(8)

[2]. Fraizer, Ernest J. The Anatomy of Human Skeleton. $4^{\text {th }}$ Edition. (1964); p5

[3]. Chatrapathi DN, Mishra BD. Positions of nutrient foramen on the shaft of the human long bones. Journal of Anatomical society of India. June 1965; 14: 54-63.

[4]. B.D.Chaurasia's - Hand book of General Anatomy. $3^{\text {rd }}$ Edition. Page 35-36

[5]. Gray's Anatomy $38^{\text {th }}$ Ed. ( 1992); p469

[6]. Murlimanju BV, Prasanth KU, Prabhu LV, Saralaya VV, Pai MM, Rai R. Morphological and topographical anatomy of nutrient foramina in human upper limb long bones and their surgical importance. Rom J Morphol Embryol . 2011; 52(3):859-862

[7]. Malukar O, Hemang Joshi H. Diaphysial Nutrient Foramina in Long Bones And Miniature Long Bones. NJIRM 2011; Vol. 2(2).page 23-26

[8]. Berard. Arch, Gener, De Med II Serie 1835; 2(7): 176-183.

[9]. Humphrey GM. Observations on the growth of the long bones and of the stumps. Medico Chir. Trans.1861; 44: 117-134.

[10]. Harris HA. Bone Growth in Health and Disease. London, Humphrey Milfords. 1933

[11]. Lutken P. Investigation into position of nutrient foramen \& direction of the vessel canals in the shaft of the humerus and femur in man. Acta. Anat. 1950; 9: 57-68.

[12]. Mysorekar VR. Diaphysial nutrient foramina in human long bones. J Anat. 1967; 101(Pt 4):813-822.

[13]. Green DP (ed). Operative hand surgery. 2nd edition. Churchill Livingstone, New York. 1988; p 1248.

[14]. Vinay G, Kumar AS. A Study of Nutrient Foramina in Long Bones of Upper Limb. Anatomica Karnataka. 2011; Vol-5, (3) Page 53-56

[15]. Hughes H. The factors determining the direction of the canal for the nutrient artery in the long bones of mammals and birds. Acta Anat (Basel). 1952; 15(3):261-280.

[16]. Payton CG. The position of the nutrient foramen and direction of the nutrient canal in the long bones of the madder-fed pig. $\mathrm{J}$ Anat. 1934; 68(Pt 4):500-510.

[17]. Longia GS, Ajmani ML, Saxena SK, Thomas RJ. Study of diaphyseal nutrient foramina in human long bones. Acta Anat (Basel). $1980 ; 107(4): 399-406$.

[18]. Henderson RG. The position of the nutrient foramen in the growing tibia and femur of the rat. J Anat. 1978; 125(Pt 3):593-599.

[19]. Lacroix P. The organization of bones. J. \& A. Churchill Ltd., London, 1951.

[20]. Kizilkanat E, Boyan N, Ozsahin ET, Soames R, Oguz O. Location, number and clinical significance of nutrient foramina in human long bones. Ann Anat. 2007; 189(1):87-95.

[21]. Schwalbe G. Zeitschrift für Anatomie und Entwicklungsgeschichte. 1876; 1:307-352.

[22]. Patake SM, Mysorekar VR. Diaphysial nutrient foramina in human metacarpals and metatarsals. J Anat. 1977; $124($ Pt 2):299-304.

[23]. Murlimanju BV, Prabhu LV, Pai MM, Yadav A, Dhananjaya KV, Prashanth KU. Neurovascular foramina of the human clavicle and their clinical significance. Surg Radiol Anat. 2011; Oct;33(8):679-82 